\title{
Integrating E-Learning Content into Enterprise Resource Planning (ERP) Curriculum
}

\author{
Paul Hawking and Brendan McCarthy \\ Victoria University, Melbourne, Australia
}

paul.hawking@vu.edu.au brendan.mccarthy@vu.edu.au

\begin{abstract}
Enterprise Resource Planning (ERP) systems offer a software-based system that handles an enterprise's total information system needs in an integrated fashion. Such systems have seen a significant growth in the last decade in the US, Europe and Australian markets and, more recently, increasing growth in Asian countries. This increase in demand for ERP systems in Asia offers opportunities for the provision of high-quality ERP education programs in the region. This paper describes the issues and barriers associated with integrating ERP systems into university curricula. It outlines the experiences of Victoria University in offering ERP education through a strategic alliance with SAP. The University is extending its offshore programs by offering ERP education in the region to take advantage of the current increase in demand in ERP applications.
\end{abstract}

To assist with the delivery of offshore ERP education an ERP e-Learning model has been developed that integrates synchronous and asynchronous content. Asynchronous e-learning does not involve the presence of a teacher. Typically the learning content is located on a web server that students can access using the Internet. Synchronous e-learning requires the learner and teacher to be present in the event at the same time. It is a real-time, instructor-led online learning event in which all participants are available at the same time and can communicate directly with each other. The model uses four technologies to facilitate teaching: application service provision (ASP), web-CT, computer-based training and virtual classroom technology. The ERP e-learning model provides an innovative and efficient means to deliver ERP curriculum. It is able to provide greater flexibility in offshore subject delivery and to maximise student learning outcomes. This is particularly relevant in light of recent international medical (SARS) and terrorists incidents.

Keywords: Enterprise Resource Planning systems, e-learning, Application Service Provider, synchronous learning, asynchronous learning, web-based learning, virtual classroom, distancelearning

\section{Introduction}

Enterprise Resource Planning (ERP) systems are modular application software that helps businesses increase the productivity of such mission-critical components as human resources, finance, parts purchasing, inventory control, supply chain and customer relationship management. ERP

Material published as part of this journal, either on-line or in print, is copyrighted by Informing Science. Permission to make digital or paper copy of part or all of these works for personal or classroom use is granted without fee provided that the copies are not made or distributed for profit or commercial advantage AND that copies 1) bear this notice in full and 2) give the full citation on the first page. It is permissible to abstract these works so long as credit is given. To copy in all other cases or to republish or to post on a server or to redistribute to lists requires specific permission from the publisher at Publisher@InformingScience.org systems are enterprise-wide and claim to incorporate best business practice that replaces legacy systems and current business processes.

In a recent study of 92 Australian organisations, Enterprise Resource Planning (ERP) systems were identified as the information technology 
Integrating E-Learning Content

project which delivered most value to their organisation (Bajkowski, 2003). While there have been a number of widely publicised ERP systems implementation failures (Calegero, 2000), ERP systems are considered by many organisations as an essential IT infrastructure. A survey of 800 U.S. companies showed that almost half of these companies had installed an ERP system and that these systems were commanding $43 \%$ of a company's application budget (Carlino, 1999) while research into U.S. Fortune 1000 companies found that over $60 \%$ have implemented an ERP system (Piturro, 1999; Stein, 1999). The market penetration of ERP systems varies considerably from industry to industry. A report by Computer Economics Inc. stated that $76 \%$ of manufacturers, 35\% of insurance and health care companies, and 24\% of Federal Government agencies already have an ERP system or are in the process of installing one (Stedman, 1999). The global market for ERP software, which was $\$ 16.6$ billion in 1998, is expected to have a compound annual growth rate of 32\%, reaching more than $\$ 66$ billion in sales by 2003 (Carlino, 1999) and is estimated to have had 300 billion dollars spent over the last decade (Carlino, 1999). The major vendor of ERP systems is SAP with approximately 54\% of the market (McBride, 2003). In Australia a recent report (BRW, 2002) identified the top 100 IT companies by usage; this was then compared with the SAP customer list. It was determined that 9 out of the top 12 IT users were SAP customers and $45 \%$ of the total list were also SAP users.

Many universities have identified the value of incorporating ERP systems into their curriculum. ERP systems can be used to reinforce many of the concepts covered in the business discipline (Becerra-Fernandez, Murphy, K. \& Simon, 2000; Hawking, Shackleton, \& Ramp 2001). The vendors argue that their products incorporate "world's best practice" for many of the business processes they support making them an ideal teaching tool (Watson \& Schneider, 1999).

Even though the value of including ERP systems in the curriculum has been identified, there are a number of barriers preventing this from happening. One significant hurdle is the limited knowledge and experience of academic staff charged with the responsibility of integrating ERP curriculum into their courses. ERP systems are complex and the time required for developing curriculum is far in excess of what staff have experienced for curriculum development in other areas. Those who develop the necessary understanding of a particular ERP system to develop curriculum can be lured away from the university into lucrative jobs in private industry. The shortfall of academic skills and experience is further compounded by the limited access to relevant ERP professional development activities and the continual upgrade of the ERP software. Another significant barrier to the use of ERP systems in universities is the perceived need for students to gain "handson" experience to master the concepts inherent in these types of systems (Watson et al, 1999). In the past, if a university decided to incorporate a major software product into its curricula, it would have purchased the software and set up the necessary infrastructure to support it. ERP systems themselves are expensive but there are the additional associated costs of hardware and professional development for the computer support staff together with the necessary incentives to retain these people once they are skilled. Many universities find that the barriers associated with introducing ERP systems are just too great!

An increasing number of universities are investigating strategic alliances with ERP system vendors to provide the support for incorporating ERP knowledge into their curriculum (Hawking 1998). The ERP vendor benefits from these alliances by increasing the supply of skilled graduates that can support their product thereby enhancing its marketability and lowering the cost of implementation.

The SAP University Alliance Program in Australia is an example of a strategic alliance between a number of universities and an ERP vendor. As part of its University Alliance, SAP provides their current software which is referred to as SAP R/3; they also provide technical and professional support for the integration of the ERP system into the curriculum. However it is still the responsibility of individual academics to develop the necessary curriculum and the university to provide 
the necessary infrastructure to support the system. This is reflected in the diversity and extent of curriculum activities of the universities involved in the alliance. A survey of these universities indicated that some were struggling to offer any ERP related subjects while others offered numerous subjects over many disciplines (Gable \& Rosemann, 1999).

The growth of ERP systems over the last decade in the US, Europe and Australia is reflected by the growth of the SAP University Alliance and the maturity of ERP curriculum in these countries. More recently ERP vendors are focussing their marketing efforts in the Asian region and accordingly there has been a demand for ERP, especially SAP skills in the employment market (Pinaroc, 2000). However the establishment of the SAP University Alliance has struggled in this region. This has provided opportunities for universities with established ERP curriculum to extend these offerings into the Asian region. Victoria University is one such university which has pursued these opportunities through the use of e-learning technologies. The University previously developed an e-learning model for the provision of ERP education (Hawking \& McCarthy, 2001). This model has evolved and this paper discusses the implementation of the model with particular focus on "virtual classroom" technology.

\section{The SAP Alliance at Victoria University}

The Faculty of Business and Law on behalf of Victoria University joined the University Alliance Program in 1998. Up until then university alliance members had focused SAP R/3 around one particular department rather than an overall faculty. The faculty approach was believed to be a better method to facilitate the incorporation of SAP R/3 into curriculum. ERP systems support the various business processes within an organization. The respective departments within the faculty teach these processes and therefore the faculty approach enables each department to focus on the aspects of the software which is relevant to it.

Since joining the SAP University Alliance Victoria University has developed a Graduate Certificate, Graduate Diploma and Master of Business in Enterprise Resource Planning Systems as well as incorporating SAP R/3 into several undergraduate subjects. Currently we have 15 staff teaching more than 20 subjects at both the undergraduate and postgraduate levels to approximately 700 students.

Many higher education institutions are making plans to globalise their courses. Victoria University is no exception and offers a broad range of academic programs throughout the Asian region. The international programs involve over 3000 students from Malaysia, Singapore, People's Republic of China and Bangladesh. Many of these universities have indicated that they wish to include ERP related subjects in their courses. While there have been indications that the high growth rates in the ERP market of recent years have somewhat dwindled, good growth has been maintained in many Asian markets with the expectation of continued growth in the foreseeable future (Pinaroc, 2000). SAP has established a University Alliance Program in many Asian countries to assist with provision of appropriately educated consultants to support this increased market. However even though these alliances have been established many of the universities have had difficulties in developing curriculum due to lack of skilled staff and available resources. Increasingly Asian universities are forming partnerships with western universities in an endeavour to broaden their curriculum offerings and add value for their students. Clearly there are advantages to be gained by both parties in setting up a partnership to teach different aspects of ERP systems. The provider is able to derive income to recoup some of the cost of developing curricula and maintaining systems while the receiver obtains the benefits of their students acquiring ERP education without the need to invest in hardware, staff training and curriculum development. 
Integrating E-Learning Content

In 2002 Victoria University commenced the Master of Business in ERP Systems at Sumbershire Business School, Singapore. In addition an agreement has been signed to commence our ERP masters program at the Northern Jiaotong University, P.R. of China in 2004.

\section{ERP e-Learning Model}

Victoria University has developed an e-Learning ERP model to facilitate the teaching of ERP systems in our offshore ERP programs. This model uses a number of e-learning technologies that blend synchronous and asynchronous content. Asynchronous e-learning does not involve the presence of the teacher. Typically the learning content is located on a web server that students can access using the Internet. The content can be interactive but the presence of the teacher is not required. Typically asynchronous e-learning is implemented by Web-based training (WBT) and may include online forums, threaded discussions and download materials. Synchronous elearning requires the learner and teacher to be present in the event at the same time. It is a realtime, instructor-led online learning event in which all participants are available at the same time and can communicate directly with each other.

To support offshore teaching a model for ERP e-Learning has been developed and has been applied in Singapore since 2002. It is also used in a limited way in an offshore program in Hong Kong. The model integrates synchronous and asynchronous content and integrates four major technologies which provide a comprehensive medium for online learning. The technologies are:

\section{Application Service Provision}

Application Service Provision (ASP) is responsible for providing the necessary technological infrastructure and support to host a particular software product. This enables the clients of the ASP to remotely access the software via the Internet. One of the barriers to ERP education mentioned earlier was gaining access to the ERP system and providing the necessary infrastructure. The ASP model provides a solution to overcoming this barrier.

Victoria University has configured one of its SAP servers to support the role of an ASP to its partnering universities in Asia. Students from these universities can access the SAP software at Victoria University via the Internet once they have installed the SAPgui software on their local PCs. Students can access the SAP software from anywhere in the world as if they were sitting in front of a PC at Victoria University.

The control and administration of the ERP system is still the responsibility of Victoria University and allows our Asian partners to access SAP R/3 without the need to purchase an expensive computer server and employ the necessary support staff. Through the use of clients in the SAP R/3 the system can be individually configured to suit the learning objectives of each offshore institution.

\section{Web-CT}

Web-CT is a web based tool which acts a repository of learning materials to assist students with their ERP education. Web-CT has tools for storing and delivering course materials including text, graphics, audio and video. Material can be released according to various criteria, such as date and student name.

Web-CT also has tools for organising and enhancing course material, communication tools so that chat, "internal" mail, discussion groups and whiteboards can be made available for use by students and instructors and tools for monitoring student progress and providing feedback.

In terms of ERP delivery the Web-CT site allows students to view and download subject outlines, assignments, past examination material and lectures in various formats. Students can submit assignments via the site and then view their results once the assignments have been marked. Chat 
facilities can be enabled to allow students to discuss set tutorial questions and discuss issues they have encountered. This interaction may occur between students within their tutorial, university or other universities.

Web-CT is used as the foundation to deliver the asynchronous e-learning content in the ERP offshore program.

\section{iTutor}

This tool is used for developing interactive tutorials in a simulated SAP environment. It enables the lecturer to record an action or transaction within the SAP environment and capture the screens involved to form the basis of a tutorial. After recording the tutorial, the iTutor Editor is used to edit the structure of the tutorial, define alternative paths (branching), edit instructional texts and create additional supplementary descriptive texts. This facility allows educational concepts to be inserted into tutorials using tools such as PowerPoint. The computer-based tutorials enable students to combine ERP theoretical concepts with the appropriate SAP screens and actions. Students can replay the tutorial as many times as necessary to understand the concepts.

The iTutor tool enables staff in the Asian location to have access to a repository of ERP educational materials overcoming the lack of resources barrier identified earlier. The Virtual Classroom technology is used for plenary sessions to reinforce the concepts covered and answer any questions coming out of the iTutor tutorials.

This tool has the added benefit of capturing and storing a lecturer's knowledge that can then be reused by others at a later stage either in a different subject or to assist if the lecturer is no longer available.

\section{Virtual Classroom}

There is a growing trend amongst academics to use the Internet to increase access to educational materials in a variety of ways to support the learning process (Pather \& Erwin 2000). The ASP enables access to the ERP system while the Virtual Classroom technology provides access to the curriculum.

The virtual classroom tool enables synchronous e-learning whereby the learner and teacher are present in the event at the same time. It is a real-time, instructor-led online learning event in which all participants are available at the same time and can communicate directly with each other. This virtual classroom capability is facilitated by the Centra Corporation virtual classroom software (Central Symposium) which provides the capability to deliver live, instructor-led classes direct to student desktops using fully integrated voice-over-IP technology. This is used to present theoretic concepts related to ERP Systems and practical demonstrations related to SAP software. Lesson delivery includes integrated full-duplex audio, interactive whiteboards, application sharing, breakout rooms and online surveys and evaluations. The technology allows lessons to be recorded for editing and playback.

The first stage in using this technology involves the lecturer developing the lesson in Microsoft PowerPoint format and then loading it onto the appropriate Centra server. This server can be either based in the Centra Corporation or can be established within the university. The lesson is then scheduled and the details distributed to the students. To access the lesson students require a PC with an internet connection and a set of headphones and microphone. After logging onto the server and the specified lesson a software wizard calibrates the audio settings. The students are presented with a screen similar to Figure 1. 


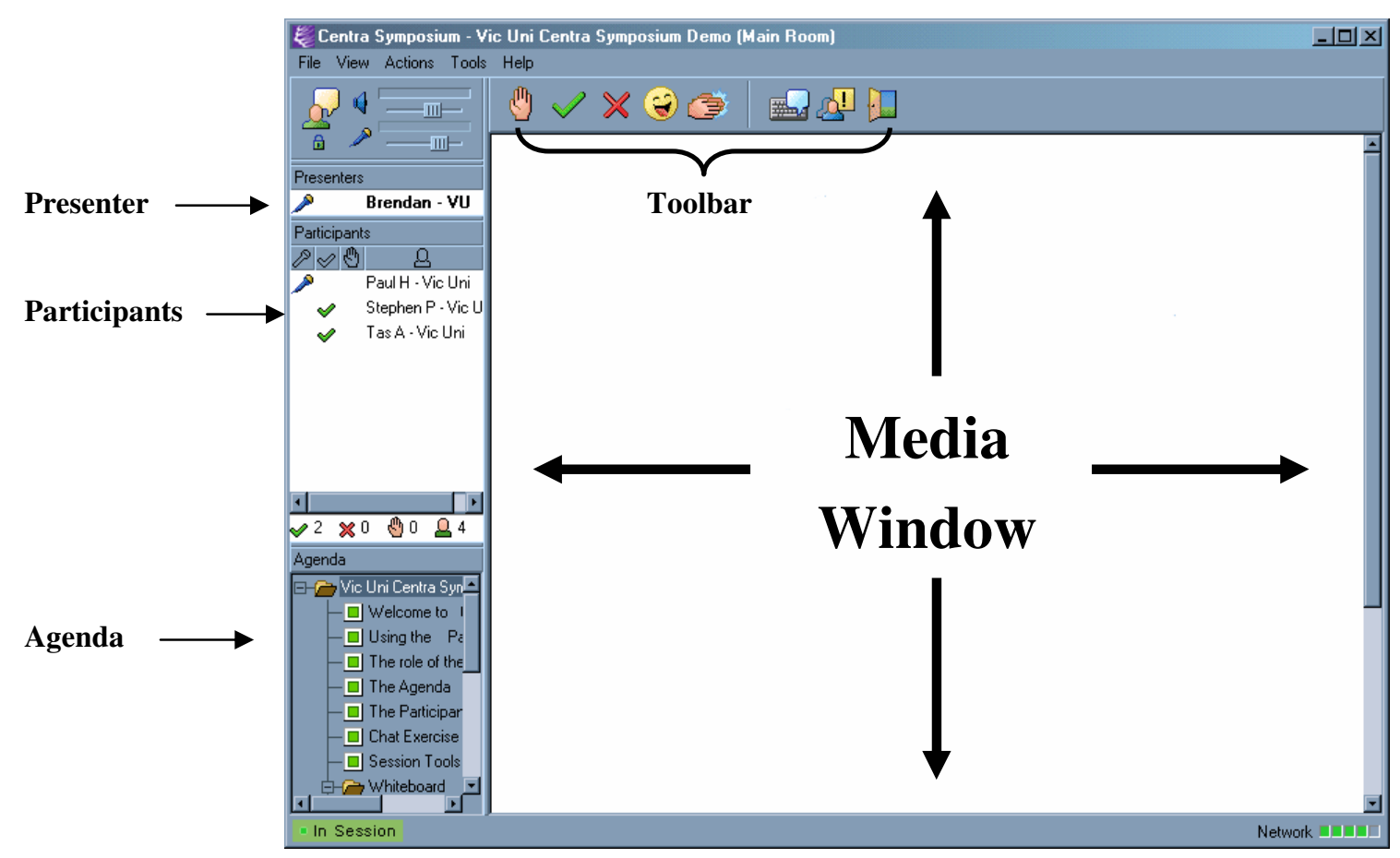

Figure 1: Centra Symposium Participant Screen

The screen is divided into a number of components. The Media Window displays the PowerPoint slides while the Agenda window displays the all the slides in the presentation. The additional windows are used to identify the presenter and other participants in the lesson. As the presenter conducts the lesson and progresses through the slides the students' screens change according to the slide and they hear the presenter's voice in real time. The presenter can also use the Media Window to demonstrate and share an application such as SAP R/3 with participants.

Centra Symposium is very powerful as it integrates many interactive tools that can be used in the live delivery. Of particular note is the "Application Sharing" tool that allows an application stored on the presenter's PC to be viewed on the students PCs. The presenter can demonstrate features of the application to students in the session and also give control of the application to individual students and allow them to utilise and manipulate the application. This is a very powerful feature and quite unique.

If a student has a query, they can "summon" the lecturer via the Virtual Classroom and the lecturer can then appropriately respond to the query. This two-way communication facilitates the interaction between the lecturer and student thus enhancing the learning process. This has been lacking in many of the online solutions up-to-date.

\section{Conclusion and Future Directions}

The four e-Learning technologies that blend synchronous and asynchronous content are not unique but combining these technologies to present ERP education is unique. They provide an avenue for ERP e-Learning using a variety of methods to cater for students' differing needs and learning styles. The ERP e-Learning initiative could provide a model for similar ERP e-Learning activities to be developed elsewhere. It is particularly relevant where recently issues such as SARS and terrorism have acted to inhibit and disrupt offshore education.

We are using the ERP e-Learning model with our partners in Singapore and Hong Kong. We are still in the early implementation stage. Once fully implemented we will carefully analyse the ef- 
fectiveness of the model. If we find it successful we plan to extend our ERP e-Learning initiative to include our other partnering universities throughout the Asian region. Beyond this we would explore the possibility of offering ERP education to anybody who enrols online into any of the subjects on offer. This would be true e-Learning as it provides the accessibility and flexibility to overcome the geographical barriers, ideologies, work commitments and traditional course structures that have prevented people from acquiring ERP knowledge and skills. Students would have the opportunity to complete the necessary assessment requirements to gain accreditation for the subject at Victoria University and appropriate certification. The successful completion of subjects would provide accreditation for a number of courses throughout the world.

The initiative has the added advantage of developing ERP knowledge of academics in the partnering universities. This has the potential to encourage future collaboration where ERP curriculum becomes a two-way process with academics from all partnering universities contributing to curriculum development.

\section{References}

Bajkowski, J. (2004). Ugly duckling ERP matures. Computerworld, 26 (10), September 2003.

Becerra-Fernandez, I. Murphy, K. \& Simon, S., (2000). Enterprise resource planning: Integrating ERP in the business school curriculum. Communications of the ACM, 43, 4 .

BRW, Business Review Weekly. (2002). The BRW 1000. Retrieved October 2002 from http://www.brw.com.au/stories/

Calegero, B. (2000). Who is to blame for ERP failure? Sunsaver, June, 2000

Carlino, J. (1999). AMR research predicts ERP market will reach $\$ 66.6$ billion by 2003 . Retrieved July 2001 from www.amrresearch.com/press/files/99518.asp

Gable, G. \& Rosemann, M. (1999). ERP in university teaching \& research: An international survey. In G. G. Gable, P. Hawking, \& T. Sinnott (Eds.), Proceedings of the 3rd Annual SAP Asia Pacific Institutes of Higher Learning Forum "Maximizing the synergy between teaching, research and business" Singapore, November 1999. SAP Australia Pty Ltd, North Sydney.

Hawking, P. (1998). Incorporating enterprise resource planning systems (SAP R/3) into university curriculum. Proceedings of the Business Information Technology Conference, Manchester, England. November 4-5, 1998.

Hawking, P. \& McCarthy, B. (2001). The ERP eLearning Model for the delivery of ERP (SAP R/3) curriculum into the Asian region. Proceedings of the Informing Science Conference, Poland, 2001.

Hawking, P. Shackleton, P., \& Ramp, A. (2001). IS'97 model curriculum and enterprise resource planning systems. Business Process Management Journal, 7 (3).

McBride, G. (2003). SAP partner kick off presentation. Sydney, 2003.

Pather, S. \& Erwin, G. (2000). Issues and challenges for web based course delivery in the South African tertiary education context. Proceedings of SAICSIT-2000, Cape Town, November 2000.

Pinaroc, J. (2000, February). ERP market in Asia still viable. Newsbytes, 18.

Piturro, M. (1999, September). How midsize companies are buying ERP. Journal of Accountancy, 41-47.

Stedman, C. (1999, August 16). What's next for ERP? Computerworld, 33, 48-49.

Stein, T. (1999, January 4). Big strides for ERP. InformationWeek, 715.

Watson, E. \& Schneider, H. (1999). Using ERP systems in education. Communication of the Association for Information Systems, 1 (9). 
Integrating E-Learning Content

\section{Biographies}

Paul Hawking is a Senior Lecturer in the School of Information Systems at Victoria University, Melbourne, Australia. He is the SAP Academic Program Director for the Faculty of Business and Law and is responsible for the facilitation of ERP education across the university. He has been involved in education delivery and curriculum development for the past twenty years and has coauthored a series of computer texts. He is currently a member of the Australian SAP User Group.

Brendan McCarthy is a Lecturer in the School of Information Systems at Victoria University, Melbourne, Australia. He is the program co-ordinator of the Master of Business in Enterprise Resource Planning Systems - Melbourne and Singapore. He has been involved in education delivery and curriculum development for the past twenty-five years and has co-authored of a series of computer texts. 